\title{
OPEN Hemiacetal-less rapamycin derivatives designed and produced by genetic engineering of a type I polyketide synthase
}

Kei Kudo ${ }^{1,6}$, Takehiro Nishimura ${ }^{2,6}$, Ikuko Kozone ${ }^{3}$, Junko Hashimoto ${ }^{3}$, Noritaka Kagaya ${ }^{3}$, Hikaru Suenaga ${ }^{1}$, Haruo Ikeda ${ }^{4} \&$ Kazuo Shin-ya ${ }^{1,5 凶}$

Engineering polyketide synthases is one of the most promising ways of producing a variety of polyketide derivatives. Exploring the undiscovered chemical space of this medicinally important class of middle molecular weight natural products will aid in the development of improved drugs in the future. In previous work, we established methodology designated 'module editing' to precisely manipulate polyketide synthase genes cloned in a bacterial artificial chromosome. Here, in the course of investigating the engineering capacity of the rapamycin PKS, novel rapamycin derivatives 1-4, which lack the hemiacetal moiety, were produced through the heterologous expression of engineered variants of the rapamycin PKS. Three kinds of module deletions in the polyketide synthase RapC were designed, and the genetically engineered vectors were prepared by the in vitro module editing technique. Streptomyces avermitilis SUKA34 transformed with these edited PKSs produced new rapamycin derivatives. The planar structures of 1-4 established based on 1D and 2D NMR, ESI-TOFMS and UV spectra revealed that 2 and 3 had skeletons well-matched to the designs, but 1 and 4 did not. The observations provide important insights into the mechanisms of the later steps of rapamycin skeletal formation as well as the ketone-forming oxygenase RapJ.

Engineering the biosynthetic enzymes that produce middle molecular weight (500-2000 Da) natural products, such as polyketides, is a powerful tool to generate new derivatives difficult to access through conventional synthesis ${ }^{1}$. Recently, we have established gene manipulating methodology for large and highly repetitive genes, especially for type I modular polyketide synthases (PKSs), in a highly precise manner ${ }^{2}$. In general, PKSs are comprised of multiple functional modules, and each is responsible for a C2-unit elongation of the growing polyketide chain. In a typical module, an acyltransferase (AT) domain specifically loads a malonyl- or methylmalonyl-extender unit onto an acyl carrier protein (ACP) domain. A ketosynthase (KS) domain catalyzes decarboxylative condensation between the extender unit and the growing chain, which is loaded by an ACP domain from the previous module. The nascent $\beta$-keto intermediate is optionally modified by ketoreductase (KR) domain, KR-dehydratase (DH) didomain or KR-DH-enoylreductase (ER) tridomain to give $\beta$-hydroxy, $\alpha, \beta$-olefinic or $\beta$-methylene substructure, respectively. The domain organization of each module encoded in the biosynthetic gene(s) corresponds to the chemical structure of the secondary metabolite, which is refered to as collinearity. Thus, a genetic modification including the deletion, insertion and replacement within a module of interest alters the function of the PKS if the overall system accepts the edit ${ }^{2-4}$. The genetically engineered host, Streptomyces avermitilis SUKA, which does not produce any endogenous secondary metabolites ${ }^{5,6}$, can be used to readily evaluate whether genetic modifications of target PKS genes have resulted in the production of desired natural product derivatives ${ }^{2}$. In the course of investigating the flexibility of the rapamycin PKS, we constructed three module-deleted genes to remove the six-membered hemiacetal ring moiety of rapamycin. Rapamycin is not only clinically used as an immunosuppressant, but also known as an antitumoral and anti-aging agent, that attracts continuous interest in the development of this natural product. Studies on the crystal structure and

\footnotetext{
${ }^{1}$ National Institute of Advanced Industrial Science and Technology (AIST), 2-4-7 Aomi, Koto-ku, Tokyo, Japan. ${ }^{2}$ Technology Research Association for Next Generation Natural Products Chemistry, 2-4-7 Aomi, Koto-ku, Tokyo, Japan. ${ }^{3} J a p a n$ Biological Informatics Consortium (JBIC), 2-4-32 Aomi, Koto-ku, Tokyo, Japan. ${ }^{4}$ Kitasato Institute for Life Sciences, Kitasato University, 1-15-1 Kitasato, Minami-ku, Sagamihara, Kanagawa, Japan. ${ }^{5}$ Biotechnology Research Center, The University of Tokyo, 1-1-1 Yayoi, Bunkyo-ku, Tokyo, Japan. ${ }^{6}$ These authors contributed equally: Kei Kudo and Takehiro Nishimura. ${ }^{凶}$ email: k-shinya@aist.go.jp
} 


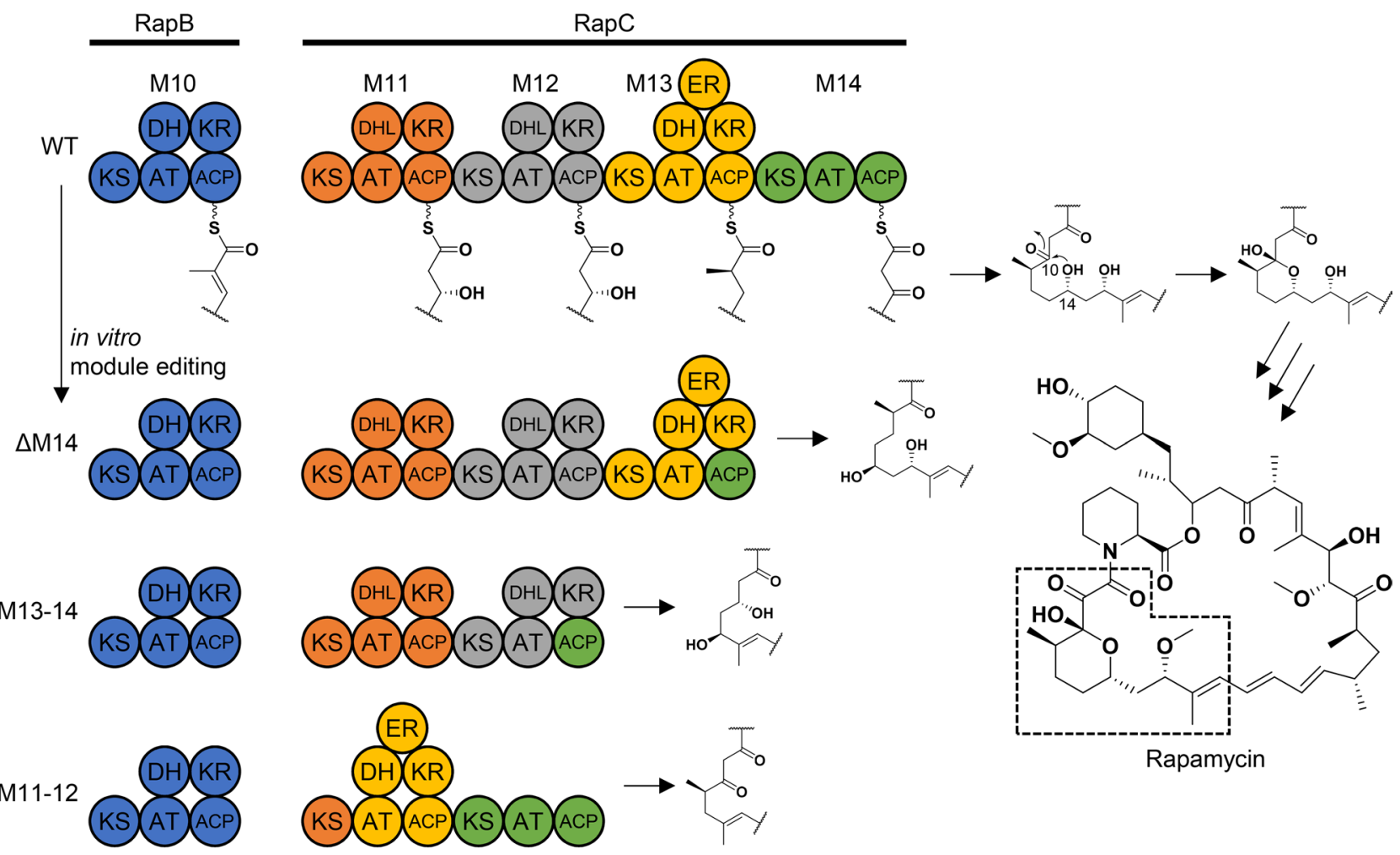

Figure 1. Domain organizations of PKSs edited to produce hemiacetal-less rapamycin derivatives. The circles represent each domain and are colored based on the traditional module boundary (start before KS and end after ACP). The polyketide substructure proposed to be biosynthesised by each engineered PKS is shown. For clarity, modules 5 to 9 of RapB are omitted. We achieved $\Delta \mathrm{M} 14$ and $\Delta \mathrm{M} 13-14$ by setting the editing point at the KR-ACP linker region, whereas the KS-AT linker region was used for $\Delta \mathrm{M} 11-12$. Unlike the wild-type product of RapC, the designed intermediates are supposed to lack the hydroxyl or the ketone for forming the six-membered hemiacetal ring. $K S$ ketosyntase, $A T$ acyltransferase, $A C P$ acyl carrier protein, $K R$ ketoreductase, $D H$ dehydratase, $D H L$ dehydratase-like (inactive), ER enoylreductase. Dashed box corresponds to the partial structures proposed to be biosynthesized by each construct.

structure-activity-relationship revealed that rapamycin binds to FK506 binding protein 12 (FKBP12) through the triketo pipecolyl substructure and recruits the mechanistic target of rapamycin (mTOR) to form a ternary complex (FKBP12-rapamycin-mTOR) to result in the inhibition of mTOR signalling pathway. To our knowledge, studies on the removal of the hemiacetal substructure of rapamycin have not been conducted. On the other hand, the smaller and structurally related analogues of rapamycin, such as nocardiopsins, show FKBP12-binding properties even though they do not possess any hemiacetal rings ${ }^{7}$. Together, the hemiacetal-less derivatives of rapamycin may provide important information for the structure-activity-relationships of this class of bioactive natural products. This paper describes the genetic manipulation of the rapamycin PKS genes and the fermentation, isolation, structural elucidation and biological activities of newly generated rapamycin derivatives.

\section{Results}

Construction of module-edited gene clusters. The experimental strategy to remove the hemiacetal substructure from rapamycin is summarized in Fig. 1. Three PKS polypeptidess, RapA, RapB and RapC, biosynthesize the polyketide backbone of rapamycin, and the non-ribosomal peptide synthetase RapP incorporates a pipecolic acid (Supplementary Fig. S1). RapP also catalyses macro-cyclization, leading to the production of pre-rapamycin (Supplementary Fig. S1). It is proposed that the hydroxyl group of C-14 attacks the C-10 ketone to form a hemiacetal ring of rapamycin (Fig. 1). Thus, we focused on the deletion of the module(s) responsible for the C-10 ketone or its $\delta$-hydroxyl, which could yield hemiacetal-less rapamycin derivatives. Based on the functional predictions of each module in RapC, the deletion of module 14 ( $\Delta \mathrm{M} 14)$, modules 13 and $14(\Delta \mathrm{M} 13$ $14)$ and modules 11 and $12(\Delta \mathrm{M} 11-12)$ were selected as targets. Because the linker region between a KR domain and an ACP is tolerant for deleting the modules of the rapamycin $\mathrm{PKS}^{8}$, we followed this strategy to construct the $\triangle \mathrm{M} 14$ and $\triangle \mathrm{M} 13-14$ vectors. In addition, by preserving the ACP domain and the following docking domain of module 14 protein-protein interaction between RapC and RapP are not expected to be disrupted. Based on the sequence alignment of the regions between KR and ACP domains, we set the upstream cutting site three residues after the Arg-Arg-Ala-Ala sequence conserved at the C-terminal end of the KR domains of the rapamycin PKSs (Supplementary Fig. S2). As well, the downstream cutting site was set six residues after the Gln-Arg-Tyr-Trp (the conserved LPTYxFxxxxxW motif of the post-AT linker) sequence (Supplementary Fig. S2). The junctions of the resulting module-deleted constructs are listed in Supplementary Table S1. In constructing the $\Delta \mathrm{M} 11-12$ vector, 
the difficulty in genetic manipulation lies between the $r a p B$ and $r a p C$ genes because they are not consecutively located in the biosynthetic gene cluster (Supplementary Fig. S1). To avoid this, we applied another strategy that uses the linker region between a KS and an AT domain as an editing point (Supplementary Fig. S2). This strategy follows the recently suggested updated module hypothesis ${ }^{9,10}$, which has been shown to work well in the generation of hybrid PKSs employing the venemycin and pikromycin $\mathrm{PKSs}^{4}$. The protein-protein interaction between RapB and RapC, mediated by the docking domains located at the C-terminal and N-terminal ends of each protein, is preserved in this case.

In vitro module editing was carried out on pKU503rap (GenBank accession number: LC566301.1) to obtain a module-deleted construct. The original BAC was digested by Cas9 with three pairs of designed sgRNAs (Supplementary Table S2) to give linearised dsDNA. The digested BAC vector was successfully ligated to each donor DNA fragment by Gibson assembly (Supplementary Table S3), yielding pKU503rap $\Delta$ M14, pKU503rap $\Delta$ M $13-14$ and pKU503rap $\Delta \mathrm{M} 11-12$, respectively.

Heterologous production of hemiacetal-less rapamycin derivatives. The three vectors were introduced into S. lividans TK24 carrying the SAP1 vector. Subsequently, the SAP1 vectors harbouring the edited gene clusters were transferred by conjugation to S. avermitilis SUKA34::rapH, which harbours an extra copy of the positive transcriptional regulator $r a p H$ in its genome to maximize production ${ }^{2,11}$. The transformants were cultured as described previously ${ }^{2}$, and we analyzed the production of rapamycin derivatives using UPLC-TOFMS (Supplementary Figs. S3-S5). Consequently, in all three cases, peaks showing the characteristic UV absorbance at $280 \mathrm{~nm}$ from the triene moiety were observed. The products, 1 from $\Delta \mathrm{M} 14,2$ from $\Delta \mathrm{M} 13-14$ and 3 from $\Delta \mathrm{M} 11-12$, were isolated from the ethyl acetate extracts of the fermentation broth by the sequential chromatography on silica gel column MPLC, gel filtration and preparative reversed-phase HPLC. The $\triangle \mathrm{M} 11-12$ construct also produced $\mathbf{4}$ as an unexpected congener, as shown below (Fig. 3). The yields of four new compounds were $0.69 \pm 0.19,3.84 \pm 1.27,3.04 \pm 1.47$ and $1.18 \pm 0.59 \mathrm{mg} / \mathrm{L}$, respectively, which were equivalent to $8,45,35$ and $14 \%$ of the rapamycin yield $(8.6 \mathrm{mg} / \mathrm{L})^{2}$, respectively.

Structural determination. The molecular formula of $\mathbf{1}$ was established to be $\mathrm{C}_{48} \mathrm{H}_{75} \mathrm{NO}_{12}$ through an $[\mathrm{M}+\mathrm{Na}]^{+}$ion at $\mathrm{m} / z 880.5192$ (calcd for $\mathrm{C}_{48} \mathrm{H}_{76} \mathrm{NO}_{12} \mathrm{Na}^{+}, 880.5181$ ) observed by high-resolution electrospray ionization mass spectrometry (HR-ESI-MS; Supplementary Fig. S3), which indicated the loss of a C3 unit from rapamycin $\left(\mathrm{C}_{51} \mathrm{H}_{79} \mathrm{NO}_{13}\right)$. The structure 1 was established on the basis of a series of $2 \mathrm{D} \mathrm{NMR}$ analyses, including DQF-COSY, HSQC and HMBC, together with the comparison of ${ }^{1} \mathrm{H}$ and ${ }^{13} \mathrm{C}$ chemical shift values ${ }^{12}$ and $2 \mathrm{D}$ NMR correlations with those of rapamycin. The tabulated ${ }^{1} \mathrm{H}$ and ${ }^{13} \mathrm{C}$ chemical shift values are shown in Table 1. Analyses of DQF-COSY revealed six ${ }^{1} \mathrm{H}$ spin sequences, most of which were identical to those of rapamycin. The sequence from methylene protons $31-\mathrm{H}_{2}\left(\delta_{\mathrm{H}} 2.92,2.64\right)$ to methylene protons $40-\mathrm{H}_{2}\left(\delta_{\mathrm{H}} 1.72,0.92\right)$ through an oxymethine proton $32-\mathrm{H}\left(\delta_{\mathrm{H}} 5.20\right)$, a methine proton $33-\mathrm{H}\left(\delta_{\mathrm{H}} 1.97\right)$, which was, in turn ${ }^{1} \mathrm{H}$ spin-coupled to methyl protons $46-\mathrm{H}_{3}\left(\delta_{\mathrm{H}} 0.86\right)$, methylene protons $34-\mathrm{H}_{2}\left(\delta_{\mathrm{H}} 1.12,1.06\right)$, a methine proton $35-\mathrm{H}\left(\delta_{\mathrm{H}} 1.42\right)$, methylene protons $36-\mathrm{H}_{2}\left(\delta_{\mathrm{H}} 2.07,0.65\right)$, an oxymethine proton $37-\mathrm{H}\left(\delta_{\mathrm{H}} 2.90, \delta_{\mathrm{C}} 84.3\right)$, an oxymethine proton $38-\mathrm{H}\left(\delta_{\mathrm{H}} 3.28, \delta_{\mathrm{C}} 73.9\right)$ and methylene protons $39-\mathrm{H}_{2}\left(\delta_{\mathrm{H}} 1.86,1.27\right)$ was observed. ${ }^{1} \mathrm{H}$ spin couplings among an olefin proton $28-\mathrm{H}\left(\delta_{\mathrm{H}} 5.21\right)$, a methine proton $29-\mathrm{H}\left(\delta_{\mathrm{H}} 3.53\right)$ and methyl protons $45-\mathrm{H}_{3}\left(\delta_{\mathrm{H}} 0.974\right)$ and between oxymethine protons $25-\mathrm{H}\left(\delta_{\mathrm{H}} 3.96\right)$ and $26-\mathrm{H}\left(\delta_{\mathrm{H}} 4.10\right)$ revealed a propyl and 1,2-dihydroxy ethyl moieties, respectively. A chain substructure involving a triene moiety was established by the ${ }^{1} \mathrm{H}$ sequence from an olefin proton $16-\mathrm{H}\left(\delta_{\mathrm{H}} 6.18\right)$ to methyl protons $43-\mathrm{H}_{3}\left(\delta_{\mathrm{H}} 0.967\right)$ through olefin protons $17-\mathrm{H}\left(\delta_{\mathrm{H}} 6.51\right), 18-\mathrm{H}$ $\left(\delta_{\mathrm{H}} 6.29\right), 19-\mathrm{H}\left(\delta_{\mathrm{H}} 6.24\right)$ and $20-\mathrm{H}\left(\delta_{\mathrm{H}} 5.50\right)$, a methine proton $21-\mathrm{H}\left(\delta_{\mathrm{H}} 2.29\right)$, which showed a correlation with methyl protons $42-\mathrm{H}_{3}\left(\delta_{\mathrm{H}} 1.02\right)$, methylene protons $22-\mathrm{H}_{2}\left(\delta_{\mathrm{H}} 1.52,1.16\right)$ and a methine proton $23-\mathrm{H}\left(\delta_{\mathrm{H}} 2.73\right)$. A strange substructure, which does not exist in rapamycin, was established as a 1,3-dihydroxybutyl moiety by the sequence from methylene protons $11-\mathrm{H}_{2}\left(\delta_{\mathrm{H}} 2.67\right)$ to an oxymethine proton $14-\mathrm{H}\left(\delta_{\mathrm{H}} 3.82\right)$ through an oxymethine proton $12-\mathrm{H}\left(\delta_{\mathrm{H}} 4.04\right)$ and methylene protons $13-\mathrm{H}_{2}\left(\delta_{\mathrm{H}} 1.70,1.65\right)$. Finally, the remaining spin coupling systems between an $\alpha$-methine proton $2-\mathrm{H}\left(\delta_{\mathrm{H}} 5.19, \delta_{\mathrm{C}} 51.7\right)$ and methylene protons $3-\mathrm{H}_{2}\left(\delta_{\mathrm{H}} 1.72\right.$, $0.92)$ and between methylene protons $5-\mathrm{H}_{2}\left(\delta_{\mathrm{H}} 1.59,1.41\right)$ and nitrogen-bonded methylene protons $6-\mathrm{H}_{2}\left(\delta_{\mathrm{H}}\right.$ $\left.3.59,2.97, \delta_{\mathrm{C}} 43.9\right)$ established two ethyl moieties, which are members of a pipecolic acid substructure, as shown below (Fig. 2).

The connectivity among these substructures was established by ${ }^{1} \mathrm{H}-{ }^{13} \mathrm{C}$ long-range couplings in the $\mathrm{HMBC}$ spectrum. According to the gene modification of the rapamycin biosynthetic gene cluster, 1 could have pipecolic acid moiety, but its six-membered ring structure could not be confirmed by DQF-COSY due to signal overlaps. ${ }^{1} \mathrm{H}-{ }^{13} \mathrm{C}$ long-range couplings from the $\alpha$-methine proton $2-\mathrm{H}$ and the methylene protons $6-\mathrm{H}_{2}$ to a methylene carbon $\mathrm{C}-3\left(\delta_{\mathrm{C}} 32.3\right)$ and from the $\alpha$-methine proton $2-\mathrm{H}$ to the nitrogen-bonded methylene carbon $\mathrm{C}-6$ and an ester carbonyl carbon $\mathrm{C}-1\left(\delta_{\mathrm{C}} 177.2\right)$ confirmed the existence of a pipecolic acid moiety. HMBC correlations from the methylene protons $31-\mathrm{H}_{2}$ and the methyl proton $45-\mathrm{H}_{3}$ to a carbonyl carbon $\mathrm{C}-30\left(\delta_{\mathrm{C}} 207.7\right)$, from the singlet methyl protons $44-\mathrm{H}_{3}\left(\delta_{\mathrm{H}} 1.85\right)$ to olefinic carbons $\mathrm{C}-27\left(\delta_{\mathrm{C}} 137.6\right), \mathrm{C}-28\left(\delta_{\mathrm{C}} 126.7\right)$ and an oxymethine carbon $\mathrm{C}-26\left(\delta_{\mathrm{C}} 77.4\right)$, from the oxymethine proton $25-\mathrm{H}$ and the methyl protons $43-\mathrm{H}_{3}$ to a carbonyl carbon $\mathrm{C}-24\left(\delta_{\mathrm{C}} 211.3\right)$ and from the singlet methyl protons $41-\mathrm{H}_{3}\left(\delta_{\mathrm{H}} 1.68\right)$ to an oxymethine carbon C-14 $\left(\delta_{\mathrm{C}} 85.0\right)$, olefinic carbons $\mathrm{C}-15\left(\delta_{\mathrm{C}} 136.7\right)$ and C-16 $\left(\delta_{\mathrm{C}} 128.9\right)$ elucidated the ${ }^{13} \mathrm{C}$ sequence from $\mathrm{C}-11$ to $\mathrm{C}-40 .{ }^{1} \mathrm{H}-{ }^{13} \mathrm{C}$ long-range couplings from the methylene protons $11-\mathrm{H}_{2}$ and the methylene protons $9-\mathrm{H}_{2}\left(\delta_{\mathrm{H}} 3.59,2.67\right)$ to a carbonyl carbon C-10 $\left(\delta_{\mathrm{C}} 203.6\right)$, from the methylene protons $9-\mathrm{H}_{2}$ and the $\alpha$-methine proton $2-\mathrm{H}$ to an amide carbonyl carbon C-8 $\left(\delta_{\mathrm{C}} 166.6\right)$ and from the oxymethine proton $32-\mathrm{H}$ to a carbonyl carbon C-1 established the main skeletal ring structure of 1 . Three methoxy protons, $47-\mathrm{H}\left(\delta_{\mathrm{H}} 3.12\right), 48-\mathrm{H}\left(\delta_{\mathrm{H}} 3.23\right)$ and $49-\mathrm{H}\left(\delta_{\mathrm{H}} 3.32\right)$, are long-range coupled to C-14, C-25 $\left(\delta_{\mathrm{C}} 85.2\right)$ and C-37 $\left(\delta_{\mathrm{C}} 84.3\right)$, which proved the substitution carbons of these methoxy groups. Overall, the structure including stereochemistry deduced from the interpretation of the 


\begin{tabular}{|c|c|c|}
\hline No & $\delta_{\mathrm{C}}$ & $\delta_{\mathrm{H}}$ (multiplicity, $J$ in $\mathrm{Hz}$ ) \\
\hline 1 & 177.2 & \\
\hline 2 & 51.7 & $5.19(\mathrm{~m})$ \\
\hline 3 & 26.0 & $2.23(\mathrm{~d}, 13.7), 1.53(\mathrm{~m})$ \\
\hline 4 & 20.5 & $1.67(\mathrm{~m}), 1.37(\mathrm{~m})$ \\
\hline 5 & 25.1 & $1.59(\mathrm{~m}), 1.41(\mathrm{~m})$ \\
\hline 6 & 43.9 & $3.59(\mathrm{~d}, 12.7), 2.97(\mathrm{dd}, 3.0,13.0)$ \\
\hline 8 & 166.6 & \\
\hline 9 & 50.5 & $3.86(\mathrm{~d}, 16.3), 3.52(\mathrm{~d}, 16.3)$ \\
\hline 10 & 203.6 & \\
\hline 11 & 50.1 & $2.67(\mathrm{~m})$ \\
\hline 12 & 65.4 & $4.04(\mathrm{~m})$ \\
\hline 13 & 41.0 & $1.70(\mathrm{~m}), 1.65(\mathrm{~m})$ \\
\hline 14 & 85.0 & $3.82(\mathrm{q}, 7.4)$ \\
\hline 15 & 136.7 & \\
\hline 16 & 128.9 & $6.18(\mathrm{~d}, 11)$ \\
\hline 17 & 127.2 & $6.51(\mathrm{dd}, 11.2,13.9)$ \\
\hline 18 & 132.7 & $6.29(\mathrm{dd}, 10.7,14.0)$ \\
\hline 19 & 131.1 & $6.24(\mathrm{dd}, 10.2,14.3)$ \\
\hline 20 & 139.5 & $5.50(\mathrm{dd}, 9.4,14.1)$ \\
\hline 21 & 36.0 & $2.29(\mathrm{~m})$ \\
\hline 22 & 39.5 & $1.52(\mathrm{~m}), 1.16(\mathrm{~m})$ \\
\hline 23 & 40.9 & $2.73(\mathrm{~m})$ \\
\hline 24 & 211.3 & \\
\hline 25 & 85.2 & $3.96(\mathrm{~d}, 6.4)$ \\
\hline 26 & 77.4 & $4.10(\mathrm{~d}, 5.6)$ \\
\hline 27 & 137.6 & \\
\hline 28 & 126.7 & $5.21(\mathrm{~d}, 4.4)$ \\
\hline 29 & 46.0 & $3.53(\mathrm{~m})$ \\
\hline 30 & 207.7 & \\
\hline 31 & 40.4 & $2.92(\mathrm{~m}), 2.64(\mathrm{~m})$ \\
\hline 32 & 74.0 & $5.20(\mathrm{~m})$ \\
\hline 33 & 32.9 & $1.97(\mathrm{~m})$ \\
\hline 34 & 39.5 & $1.12(\mathrm{~m}), 1.06(\mathrm{~m})$ \\
\hline 35 & 33.1 & $1.42(\mathrm{~m})$ \\
\hline 36 & 35.5 & $2.07(\mathrm{~m})$, ovl; $0.65(\mathrm{q}, 11.6)$ \\
\hline 37 & 84.3 & $2.90(\mathrm{~m})$, ovl \\
\hline 38 & 73.9 & $3.28(\mathrm{~m})$ \\
\hline 39 & 32.3 & $1.86(\mathrm{~m})$, ovl; $1.27(\mathrm{~m})$ \\
\hline 40 & 31.0 & $1.72(\mathrm{~m}), 0.92(\mathrm{~m})$ \\
\hline 41 & 9.7 & $1.68(\mathrm{~s})$ \\
\hline 42 & 21.3 & $1.02(\mathrm{~d}, 6.5)$ \\
\hline 43 & 13.4 & $0.967(\mathrm{~d}, 6.5)$ \\
\hline 44 & 12.2 & $1.85(\mathrm{~s})$ \\
\hline 45 & 14.8 & $0.974(\mathrm{~d}, 6.5)$ \\
\hline 46 & 15.3 & $0.86(\mathrm{~d}, 6.8)$ \\
\hline 47 & 55.0 & $3.12(\mathrm{~s})$ \\
\hline 48 & 57.1 & $3.23(\mathrm{~s})$ \\
\hline 49 & 56.2 & $3.35(\mathrm{~s})$ \\
\hline
\end{tabular}

Table 1. ${ }^{13} \mathrm{C}$ and ${ }^{1} \mathrm{H}$ NMR spectroscopic data for 1 in acetone- $d_{6}(150 / 600 \mathrm{MHz}$, respectively).

biosynthetic gene cluster of 1 was determined, as shown in Fig. 2. The structure was not expected to be produced from the modified biosynthetic gene cluster $(\Delta \mathrm{M} 14)$ of rapamycin (see Fig. 1$)$. In particular, according to the sequence of the AT domain of module 13, 1 should possess a methyl group at the C-9 position.

Compound 2, which was obtained from SUKA34::rapH/pKU503rap $\Delta \mathrm{M} 13-14$, has a molecular formula of $\mathrm{C}_{45} \mathrm{H}_{71} \mathrm{NO}_{11}$ determined by an $[\mathrm{M}+\mathrm{Na}]^{+}$ion at $m / z 824.4913$ (calcd for $\mathrm{C}_{45} \mathrm{H}_{71} \mathrm{NO}_{11} \mathrm{Na}^{+}, 824.4919$ ) in an HR-ESI-MS (Supplementary Fig. S4). Analyses of the 2D NMR spectra of 2 revealed that the skeletal structure 


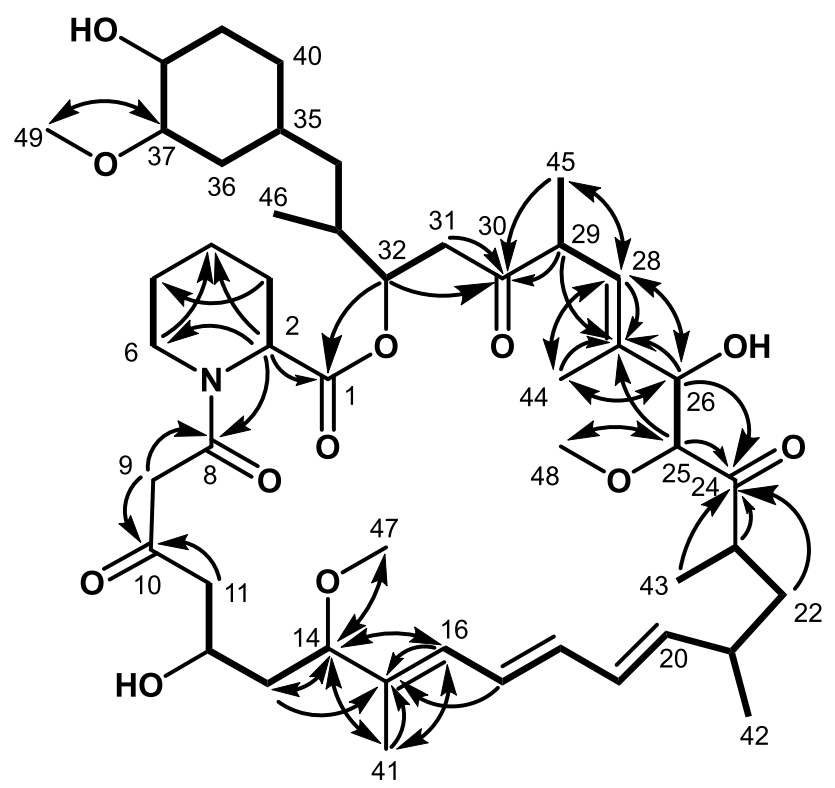

Figure 2. 2D NMR analysis of $\mathbf{1}$. Bold lines and arrows show DQF-COSY and HMBC correlations, respectively.

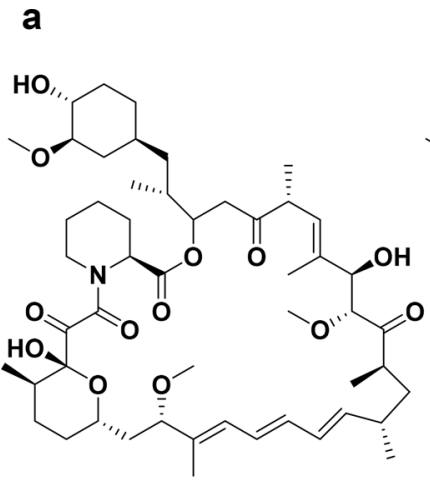

Rapamycin

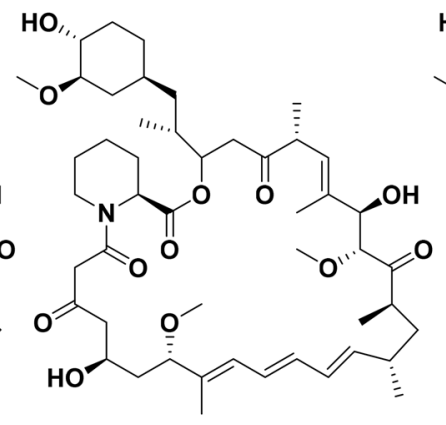

1

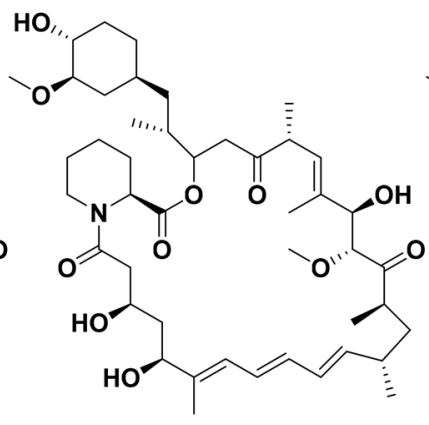

2

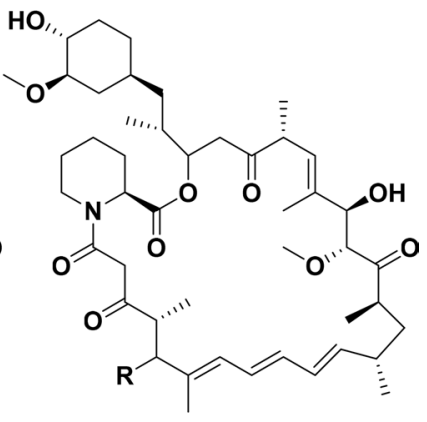

3, $\mathrm{R}=\mathrm{H}$

b

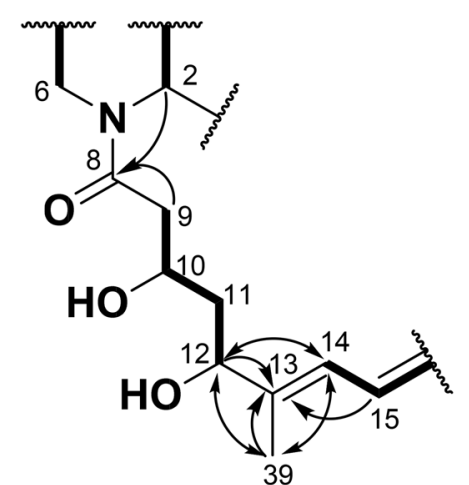

2

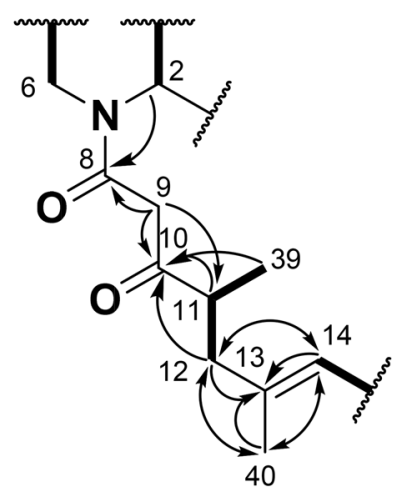

3

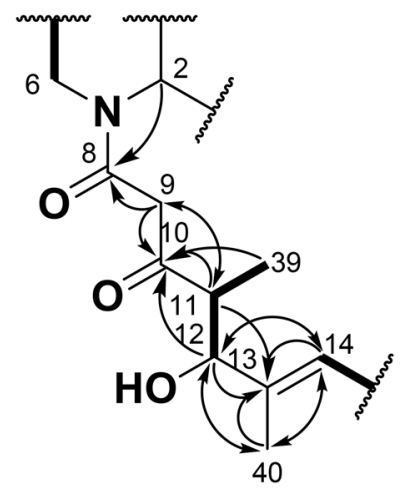

4

Figure 3. Structural determination of newly isolated hemiacetal-less rapamycin derivatives. (a) Structures of rapamycin and compounds $\mathbf{2 - 4}$. The stereochemistry of the derivatives is deduced from that of rapamycin as well as the stereoselectivities of corresponding tailoring domains. (b) Selected ${ }^{1} \mathrm{H}-{ }^{1} \mathrm{H}$ DQF-COSY and HMBC correlations in 2-4. Bold lines and arrows show DQF-COSY and HMBC correlations, respectively. 
a

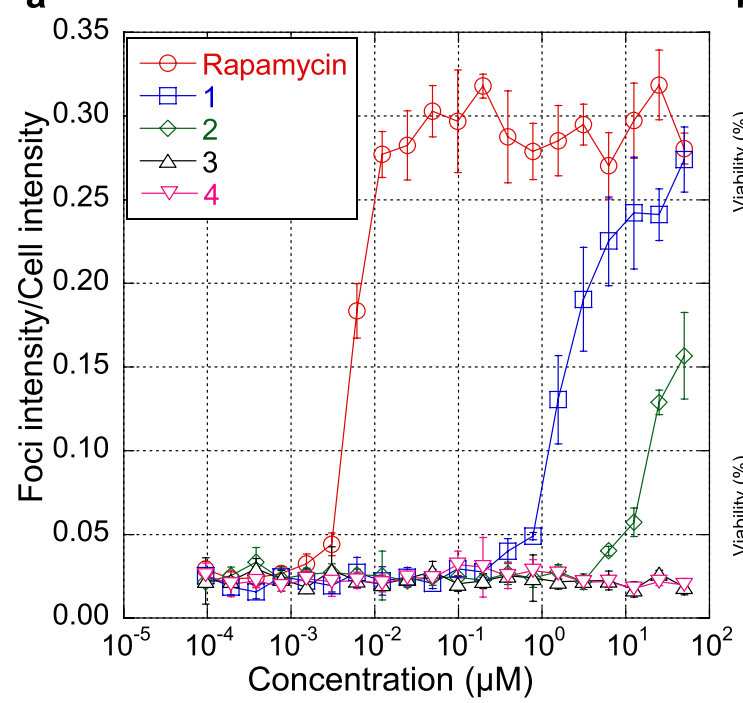

b
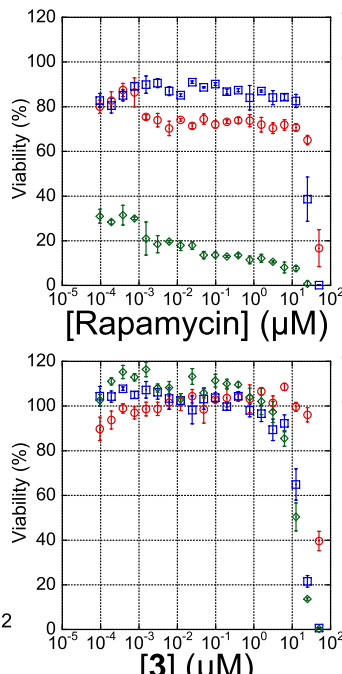

[3] $(\mu \mathrm{M})$

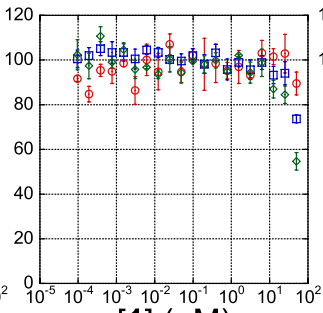

[1] $(\mu \mathrm{M})$

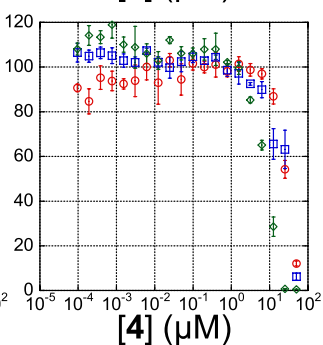

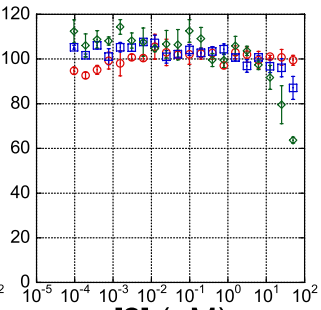

$[2](\mu \mathrm{M})$

Figure 4. Biological activities. (a) Binding activities of rapamycin and its derivatives to FKBP and mTOR. (b) cytostatic activities of rapamycin and its derivatives to SKOV-3 (red), MESO-1 (blue) and Jurkat (green) cells. Each plot with error bars indicates average \pm s.d. calculated from three independent biological replicates.

from a triene moiety to a cyclohexyl moiety together with a pipecolic acid moiety in $\mathbf{2}$ is the same as that of rapamycin, as shown in Supplementary Fig. S6. The changed structure was established as follows: the sequence from methylene protons $9-\mathrm{H}_{2}\left(\delta_{\mathrm{H}} 2.51,2.46\right)$ to an oxymethine proton $12-\mathrm{H}\left(\delta_{\mathrm{H}} 4.37\right)$ through an oxymethine proton $10-\mathrm{H}\left(\delta_{\mathrm{H}} 4.01\right)$ and methylene protons $11-\mathrm{H}_{2}\left(\delta_{\mathrm{H}} 1.70,1.64\right)$ was observed in the DQF-COSY spectra. ${ }^{1} \mathrm{H}-{ }^{13} \mathrm{C}$ long-range couplings from an $\alpha$-methine proton $2-\mathrm{H}\left(\delta_{\mathrm{H}} 5.13, \delta_{\mathrm{C}} 52.5\right)$ and the methylene protons $9-\mathrm{H}_{2}$ to an amide carbonyl carbon C- $8\left(\delta_{\mathrm{C}} 173.1\right)$ revealed the connectivity between the pipecolic acid and a 1,3 -dihydroxybutyl moiety, as shown in Fig. 3 . In addition, $\mathrm{HMBC}$ correlations from singlet methyl protons $39-\mathrm{H}_{3}\left(\delta_{\mathrm{H}}\right.$ $1.75)$ to an oxymethine carbon $\mathrm{C}-12\left(\delta_{\mathrm{C}} 76.9\right)$, olefinic carbons $\mathrm{C}-13\left(\delta_{\mathrm{C}} 141.2\right)$ and C-14 $\left(\delta_{\mathrm{C}} 126.5\right)$ established the linkage between C-12 and C-14. Thus, the 27-membered structure of 2 was elucidated as shown in Fig. 3.

The module-edited construct pKU503rap $\Delta \mathrm{M} 11-12$ produced two compounds, 3 and $\mathbf{4}$. The molecular formula of 3 was established as $\mathrm{C}_{46} \mathrm{H}_{71} \mathrm{NO}_{10}$ from an ion at $m / z 820.4980[\mathrm{M}+\mathrm{Na}]^{+}$(calcd for $\mathrm{C}_{46} \mathrm{H}_{71} \mathrm{NO}_{10} \mathrm{Na}^{+}$, 820.4970) by positive ion HR-ESI-MS data (Supplementary Fig. S5). As in the case of compounds 1 and 2, the partial structures of $\mathbf{3}$ from a triene moiety to a cyclohexyl moiety and a pipecolic acid moiety are equivalent to that of rapamycin, as shown in Supplementary Fig. S6. The sequence from methyl protons $39-\mathrm{H}_{3}\left(\delta_{\mathrm{H}} 1.14\right)$ to methylene protons $12-\mathrm{H}_{2}\left(\delta_{\mathrm{H}} 2.39,2.21\right)$ through a methine proton $11-\mathrm{H}\left(\delta_{\mathrm{H}} 3.06\right)$ indicated the presence of a propyl moiety. In the HMBC spectrum of 3 , the ${ }^{1} \mathrm{H}-{ }^{13} \mathrm{C}$ long-range couplings from an $\alpha$-methine proton $\left(\delta_{\mathrm{H}} 5.24\right)$ in the pipecolic acid and methylene protons $9-\mathrm{H}_{2}\left(\delta_{\mathrm{H}} 3.72,3.63\right)$ to an amide carbonyl carbon $\mathrm{C}-8\left(\delta_{\mathrm{C}}\right.$ 166.6), from the methylene protons $9-\mathrm{H}_{2}$ and the methyl protons $39-\mathrm{H}_{3}$ to another carbonyl carbon $\mathrm{C}-10\left(\delta_{\mathrm{C}}\right.$ $207.4)$ and from methyl protons $40-\mathrm{H}_{3}\left(\delta_{\mathrm{H}} 1.81\right)$ to methylene carbon $\mathrm{C}-12\left(\delta_{\mathrm{C}} 42.4\right)$, a quaternary olefin carbon C-13 $\left(\delta_{\mathrm{C}} 136.5\right)$ and olefinic methine carbon C-14 $\left(\delta_{\mathrm{C}} 126.2\right)$ determined the structure of 3 , as shown in Fig. 3.

The molecular formula of 4 was determined by HR-ESI-MS to be $\mathrm{C}_{46} \mathrm{H}_{71} \mathrm{NO}_{11}$ (found: $836.4904[\mathrm{M}+\mathrm{Na}]^{+}$, calculated for $\mathrm{C}_{46} \mathrm{H}_{71} \mathrm{NO}_{11} \mathrm{Na}^{+}, 836.4919$ ), which indicated that 4 is an oxidized compound of 3 (Supplementary Fig. S5). Analyses of a variety of NMR spectra revealed that the basic skeletal structure is almost identical to that of 3 (Supplementary Fig. S6). The structural difference between 3 and $\mathbf{4}$ is recognised at the position of C-12 (in $\left.3, \delta_{\mathrm{H}} 2.39,2.21, \delta_{\mathrm{C}} 42.4\right)$. The methylene C-12 was replaced by an oxymethine $\left(\delta_{\mathrm{H}} 4.24, \delta_{\mathrm{C}} 79.2\right)$ in 4.

Biological activity. To evaluate the importance of the hemiacetal moiety of rapamycin on its biological activity, we examined the activities of 1-4 to stabilize the binding between FKBP12 and mTOR by employing the Fluoppi (Fluorescent based protein-protein interactions) system ${ }^{13}$. As a result, 1 showed $\sim 1000$ times weaker activity $\left(\mathrm{EC}_{50}=1.88 \mu \mathrm{M}\right)$ than that of rapamycin $(5.6 \mathrm{nM})$ (Fig. $\left.4 \mathrm{a}\right)$. Furthermore, 2 showed much less activity, and 3 and 4 showed no detectable activity (Fig. 4a). In comparison with the other 29-membered derivatives with a hemiacetal ring that did not reduce the activity so dramatically $(\sim 10 \% \text { reduction versus rapamycin })^{2}$, these results indicate that changes in the hemiacetal and also in the diketo-moiety prevent efficient formation of the ternary complex with FKBP12 and mTOR.

Rapamycin shows cytostatic effects against human ovarian adenocarcinoma SKOV-3 cells, malignant pleural mesothelioma MESO-1 cells and T lymphoma Jurkat cells (Fig. 4b). In contrast, $\mathbf{3}$ and $\mathbf{4}$ did not show cytostatic effects but rather cytotoxic activities at relatively high concentrations, while both cytostatic and cytotoxic activities were abolished in $\mathbf{1}$ and $\mathbf{2}$. Cytotoxicities at a high concentration were also observed in the case of rapamycin. 


\section{Discussion}

Hemiacetal-less rapamycin derivatives were successfully produced through one- or two-module deletions within RapC. As with previous reports ${ }^{2,8}$, the module deletion strategy performed well in the rapamycin PKS system. The skeletons of $\mathbf{2}$ and $\mathbf{3}$ were matched the designs well, while $\mathbf{1}$ and $\mathbf{4}$ did not.

A possible interpretation of the production of the demethylated- and oxo-derivative $\mathbf{1}$ can be considered from three aspects: the substrate specificity of RapP, the extender unit specificity of the last AT domain and the functionality of the reductive loop. First, RapP may gatekeep against the $\alpha$-methyl intermediate (Supplementary Fig. S7), while $\beta$-hydroxyl or $\gamma$-methyl groups are allowed (cf. 2-4). This hypothesis also suggests that the formation of a hemiacetal ring occurs after RapP-catalyzed macrocyclisation. Second, if the AT domain of module 13 (AT13) is promiscuous in selecting an extender unit, it can cause malonyl-CoA incorporation into the growing polyketide chain. The relaxed specificity of AT domains has also been observed in an engineered erythromycin $\mathrm{PKS}^{14}$ and in AT8 of the spinosyn PKS ${ }^{15}$. Alternatively, if ACP14 cannot interact with AT13, AT12 may load malonyl-CoA onto ACP14 to yield $\mathbf{1}$. The production of 2 by the $\triangle \mathrm{M} 13-14$ construct demonstrates the sufficient interaction between ACP14 and AT12. There is also a possibility that the native malonyl-CoA:ACP transacylase from primary metabolism overrides AT13 as observed for an AT6-inactivated erythromycin PKS ${ }^{16}$. Third, the interaction between ACP14 and KR13 could be insufficient to process the $\beta$-oxo-group. Dysfunctionality of KR domains in engineered contexts has been reported in three-module systems ${ }^{17,18}$. Concerning substrate specificity, we can also predict that RapP prefers the $\beta$-oxo-intermediate to the $\beta$-methylene pattern. A relatively low yield of $\mathbf{1}(8 \%$ that of rapamycin) compared to $\mathbf{2}(45 \%)$ and $\mathbf{3}+\mathbf{4}(49 \%$ combined) may reflect the lower efficiency of these shunt processes.

The hydroxyl group at C-12 in 4 could be explained by the impaired function of the $\mathrm{DH}$ domain or the promiscuity of a P450 enzyme, such as RapJ, which catalyzes the successive oxidation at C-9 of rapamycin to form the diketo-moiety ${ }^{19}$. Interestingly, all four hemiacetal-less derivatives obtained in this study lack the C-9 keto group even though a rapamycin derivative formed through the deletion of five modules and possessing a strange ester bond is reported to have the C-9 keto group ${ }^{8}$. Although further enzymological evidence is required, this study provides important insights to understand the catalytic capability of RapJ.

The diminished biological activities of hemiacetal-less rapamycin derivatives were almost as expected. The crystal structures revealed that the hemiacetal moiety interacts with the hydrophobic cavity of $\mathrm{FKBP}^{20,21}$ and the triketo pipecolyl moiety was shown to be essential for binding to $\mathrm{FKBP}^{22}$. However, the fact that 1 retained the very weak ability to form the FKBP-1-mTOR ternary complex indicates that even the hemiacetal- and diketo-less macrocyclic skeleton could promote or inhibit some protein-protein interactions.

\section{Methods \\ Bacterial strains and culture conditions. Bacterial strains and culture conditions reported in our previ- ous work were used ${ }^{2}$. The growth of Escherichia coli strains DH5a, NEB10 $\beta$ (New England Biolabs Japan Inc., Tokyo, Japan) and GM2929 $h s d S:: T n 10^{5}$ was achieved using LB containing $10 \mathrm{~g}$ of tryptone, $5 \mathrm{~g}$ of yeast extract and $5 \mathrm{~g}$ of $\mathrm{NaCl}$ in $1 \mathrm{~L}$ of deionized water adjusted to $\mathrm{pH} 7.5$, and the solid medium (LA) was prepared by adding $15 \mathrm{~g}$ of agar to $1 \mathrm{~L}$ of LB medium. In the production of rapamycin derivatives, Streptomyces avermitilis SUKA carrying the biosynthetic gene cluster for each derivative was inoculated into a $50-\mathrm{mL}$ test tube with $15 \mathrm{~mL}$ of GSY medium containing $5 \mathrm{~g}$ of glucose, $15 \mathrm{~g}$ of soya flour and $5 \mathrm{~g}$ of yeast extract per liter of deionized water, and the cells were cultured with reciprocal shaking at $320 \mathrm{rpm}$ at $27^{\circ} \mathrm{C}$ for 2 days. A $375 \mu \mathrm{L}$ aliquot of the vegeta- tive culture was used to inoculate a $125-\mathrm{mL}$ flask containing $15 \mathrm{~mL}$ of production medium containing $40 \mathrm{~g}$ of $\beta$-cyclodextrin, $20 \mathrm{~g}$ of Pharmamedia, $5 \mathrm{~g}$ of glycerol, $21.2 \mathrm{~g}$ of MES, $5 \mathrm{mg}$ of $\mathrm{ZnSO}_{4} \cdot 7 \mathrm{H}_{2} \mathrm{O}, 5 \mathrm{mg}$ of CuSO $\mathrm{Cu}_{4} \cdot 5 \mathrm{H}_{2} \mathrm{O}$ and $5 \mathrm{mg}$ of $\mathrm{MnCl}_{2} \cdot 4 \mathrm{H}_{2} \mathrm{O}$ per liter of deionized water adjusted to $\mathrm{pH}$ 6.0. The fermentation culture was shaken at $24^{\circ} \mathrm{C}$ for 5 days at $180 \mathrm{rpm}$. Large-scale preparations of the products were carried out in a baffled 500 -mL flask containing $100 \mathrm{~mL}$ of the production medium.}

Introduction of edited BACs into S. avermitilis SUKA. The procedure follows that of our previous work $^{2}$. All clones were introduced into S. lividans TK24 carrying the SAP1 vector (containing the synthetic sequence of $a t t B \phi_{K 38-1}, a t t B_{R 4}, a t t B \phi_{B T 1}, a t t B \phi_{C 31}$ and $a t t B_{T G 1}$ of $S$. avermitilis MA-4680). All clones were integrated into the SAP1 vector because the bacteriophage attachment sites (attB) were located in the SAP1 vector but not in the chromosome. The transfer of the SAP1 vector containing the edited gene cluster for rapamycin was conducted as described ${ }^{23}$. The objective transconjugants were confirmed by the antibiotic-resistance phenotype and the size of the linear plasmid by contour-clamped homogeneous electric field (CHEF ${ }^{24}$ electrophoresis using SAP1::pKU503rap as the control linear plasmid.

In vitro module editing of the rap gene cluster on BAC. The experimental procedure followed a previously described method ${ }^{2}$. The sequences of oligonucleotides and donor DNA fragments are listed in Supplementary Tables S2 and S3, respectively. pKU503rap (GenBank accession number: LC566301.1) was digested with Cas9 and a pair of sgRNA in vitro, and the resulting linear dsDNA and corresponding donor DNA fragment were joined by Gibson assembly. Transformants were screened by PCR using corresponding primers (Supplementary Table S2).

UPLC/UV/MS analysis of the metabolites from the transformant. A $750 \mu \mathrm{L}$ aliquot of the culture was extracted with $750 \mu \mathrm{L}$ of $n$-butanol $(n-\mathrm{BuOH})$, and the organic layer was subjected to the UPLC/UV/ MS analysis. The analytical procedure follows our previous work ${ }^{2}$. Analytical UPLC and HR-ESI-MS (positive mode) were performed using a Waters ACQUITY UPLC System (Waters, Taunton, MA) in conjunction with a BEH ODS column (2.1 i.d. $\times 100 \mathrm{~mm}$, Waters), a Waters ACQUITY UPLC photodiode array e $\lambda$ detector 
(Waters) and a XevoG2 ToF system (Waters). Mobile phase A was water $+0.1 \%$ formic acid, and mobile phase $\mathrm{B}$ was acetonitrile $+0.1 \%$ formic acid. The elution program was $5-100 \%$ B over $5 \mathrm{~min}$ and $100 \% \mathrm{~B}$ for $1 \mathrm{~min}$ at a flow rate of $0.8 \mathrm{~mL} \mathrm{~min}{ }^{-1}$. Data acquisitions and analyses were performed using MassLynX V4.1 software (Waters). The yields were calculated from the peak area of UV absorption chromatogram at $280 \mathrm{~nm}$. A standard curve was prepared using rapamycin.

Isolation of compound $\mathbf{1}$. The procedure follows our previous work ${ }^{2}$. Compound $\mathbf{1}$ was isolated from SUKA34::rapH/pKU503rap $\Delta$ M14. Six liters of fermentation broth of SUKA34::rapH/pKU503rap $\Delta$ M14 were centrifuged to obtain a mycelial cake, which was extracted twice with $750 \mathrm{~mL}$ of acetone. The acetone was removed in vacuo, and the residual aqueous layer was extracted three times with ethyl acetate (EtOAc). The resultant EtOAc layer was concentrated in vacuo to afford $3.91 \mathrm{~g}$ of crude extract. The crude extract was subjected to medium-pressure liquid chromatography (MPLC) on silica gel (SNAP Ultra $25 \mathrm{~g}$, Biotage, Uppsala, Sweden) eluted with a gradient system of $n$-hexane-EtOAc (0-25\% EtOAc) followed by a stepwise solvent system of chloroform $\left(\mathrm{CHCl}_{3}\right)$-methanol $(\mathrm{MeOH})(0,1,3,5,10,50$ and $90 \% \mathrm{MeOH})$. The $3 \%$ and $5 \% \mathrm{MeOH}$ fractions $(875 \mathrm{mg})$ were combined with the EtOAc extract of the broth centrifugal supernatant $(2.05 \mathrm{~g})$ and subjected to silica gel MPLC (SNAP Ultra $25 \mathrm{~g}$ ) with isocratic elution with $4 \% \mathrm{MeOH}$ in $\mathrm{CHCl}_{3}$. The fractions were monitored by TLC and UPLC analyses, and fractions containing $\mathbf{1}(145 \mathrm{mg})$ were collected and further purified by Sephadex LH-20 column chromatography $\left(1: 1 \mathrm{CHCl}_{3} / \mathrm{MeOH}\right)$ to obtain a fraction containing 1 $(29.4 \mathrm{mg})$. Finally, the sample containing 1 was purified by preparative reversed-phase HPLC using a CAPCELL PAK MG-II C18 column $(5.0 \mu \mathrm{m}, 20$ i.d. $\times 150 \mathrm{~mm}$; Shiseido, Tokyo, Japan), and the elution with $50 \%$ aqueous acetonitrile supplemented with $0.1 \%$ formic acid yielded $2.5 \mathrm{mg}$ of $\mathbf{1}$ as a colourless oil and as a 4:1 mixture of rotamers. The assignments of ${ }^{1} \mathrm{H}$ and ${ }^{13} \mathrm{C}$ NMR signals are noted in Table 1.

Isolation of compound 2. The procedure follows our previous work ${ }^{2}$. Compound $\mathbf{2}$ was isolated from SUKA34::rapH/pKU503rap $\Delta$ M13-14. Two liters of fermentation broth of SUKA34::rapH/pKU503rap $\Delta$ M13-14 were centrifuged to obtain a mycelial cake, which was extracted twice with $250 \mathrm{~mL}$ of acetone. The acetone was removed in vacuo, and the residual aqueous layer was extracted three times with ethyl acetate (EtOAc). The resultant EtOAc layer was concentrated in vacuo to afford $1.23 \mathrm{~g}$ of crude extract. The crude extract was subjected to medium-pressure liquid chromatography (MPLC) on silica gel (SNAP Ultra 25 g, Biotage, Uppsala, Sweden) eluted with a gradient system of $n$-hexane-EtOAc (0-25\% EtOAc) followed by a stepwise solvent system of chloroform $\left(\mathrm{CHCl}_{3}\right)$-methanol $(\mathrm{MeOH})(0,1,3,5,10,50$ and $90 \% \mathrm{MeOH})$. The $3 \%$ and $5 \% \mathrm{MeOH}$ fractions $(173 \mathrm{mg})$ were combined with the EtOAc extract of the broth centrifugal supernatant $(286 \mathrm{mg})$ and subjected to silica gel MPLC (SNAP Ultra $25 \mathrm{~g}$ ) with isocratic elution with $4 \% \mathrm{MeOH}$ in $\mathrm{CHCl}_{3}$. The fractions were monitored by TLC and UPLC analyses, and fractions containing $2(23.7 \mathrm{mg})$ were collected and further purified by Sephadex LH-20 column chromatography $\left(1: 1 \mathrm{CHCl}_{3} / \mathrm{MeOH}\right)$ to obtain a fraction containing 2 (23.7 mg). Finally, the sample containing 2 was purified by preparative reversed-phase HPLC using a CAPCELL PAK MG-II C18 column (5.0 $\mu$ m, 20 i.d. $\times 150 \mathrm{~mm}$; Shiseido, Tokyo, Japan), and the elution with $50 \%$ aqueous acetonitrile supplemented with $0.1 \%$ formic acid yielded $1.3 \mathrm{mg}$ of 2 as a colorless, amorphous solid and as a $4: 1$ mixture of rotamers. The assignments of ${ }^{1} \mathrm{H}$ and ${ }^{13} \mathrm{C}$ NMR signals are noted in Supplementary Table S4.

Isolation of compounds $\mathbf{3}$ and $\mathbf{4}$. The procedure follows our previous work ${ }^{2}$. Compounds $\mathbf{3}$ and $\mathbf{4}$ were isolated from SUKA34::rapH/pKU503rap $\Delta$ M11-12. Six liters of fermentation broth of SUKA34::rapH/ pKU503rap $\Delta$ M11-12 were centrifuged to obtain a mycelial cake, which was extracted twice with $750 \mathrm{~mL}$ of acetone. The acetone was removed in vacuo, and the residual aqueous layer was extracted twice with ethyl acetate (EtOAc). The resultant EtOAc layer was concentrated in vacuo to afford $2.67 \mathrm{~g}$ of crude extract. The crude extract was subjected to medium-pressure liquid chromatography (MPLC) on silica gel (SNAP Ultra $25 \mathrm{~g}$, Biotage, Uppsala, Sweden) eluted with a gradient system of $n$-hexane-EtOAc $(0-25 \%$ EtOAc) followed by a stepwise solvent system of chloroform $\left(\mathrm{CHCl}_{3}\right)$-methanol $(\mathrm{MeOH})(0,1,3,5,10,50$ and $90 \% \mathrm{MeOH})$. The $3 \% \mathrm{MeOH}$ fraction $(405 \mathrm{mg})$ was combined with the EtOAc extract of the broth centrifugal supernatant $(757 \mathrm{mg})$ and subjected to silica gel MPLC (SNAP Ultra $25 \mathrm{~g}$ ) with isocratic elution with $4 \% \mathrm{MeOH}$ in $\mathrm{CHCl}_{3}$. The fractions were monitored by TLC and UPLC analyses, and fractions containing $3(137 \mathrm{mg})$ and $4(85.9 \mathrm{mg})$ were collected, respectively. The sample containing 3 was purified by Sephadex LH-20 column chromatography $\left(1: 1 \mathrm{CHCl}_{3} /\right.$ $\mathrm{MeOH})$ to obtain a fraction containing $3(34.1 \mathrm{mg})$. Finally, purification by preparative reversed-phase HPLC using a CAPCELL PAK MG-II C18 column $(5.0 \mu \mathrm{m}, 20$ i.d. $\times 150 \mathrm{~mm}$; Shiseido, Tokyo, Japan $)$ and the elution with $60 \%$ aqueous acetonitrile supplemented with $0.1 \%$ formic acid yielded $9.8 \mathrm{mg}$ of 3 as a white, amorphous solid as a 4:1 mixture of rotamers. Similarly, the sample containing $\mathbf{4}$ was purified by Sephadex LH-20 column chromatography $\left(1: 1 \mathrm{CHCl}_{3} / \mathrm{MeOH}\right)$ to obtain a fraction containing $4(13.0 \mathrm{mg})$. Finally, purification by preparative reversed-phase HPLC using a CAPCELL PAK MG-II C18 column $(5.0 \mu \mathrm{m}, 20$ i.d. $\times 150$ mm; Shiseido, Tokyo, Japan) was performed, and the elution with $40 \%$ aqueous acetonitrile supplemented with $0.1 \%$ formic acid yielded $1.9 \mathrm{mg}$ of 4 as a white amorphous solid as a $4: 1$ mixture of rotamers. The assignments of ${ }^{1} \mathrm{H}$ and ${ }^{13} \mathrm{C}$ NMR signals are noted in Supplementary Table S5.

Binding activities of rapamycin derivatives to FKBP and mTOR. The procedure is same as our previous work ${ }^{2}$. HeLa cells were maintained in DMEM (Fujifilm Wako, Osaka, Japan) supplemented with $10 \%$ FBS (Thermo Fisher Scientific, MA, USA) and $1 \%$ of Penicillin-Streptomycin (Thermo Fisher Scientific) in a humidified incubator with $5 \% \mathrm{CO}_{2}$ at $37^{\circ} \mathrm{C}$. Harvested cells were plated at $1 \times 10^{6}$ cells/well in a 6-well plate and incubated for $6 \mathrm{~h}$. Each $1.25 \mu \mathrm{g}$ of phAG-mTOR and pAsh-FKBP12 (Medical \& Biological Laboratories Co., Ltd., Aichi, Japan) was co-transfected with Lipofectamine 2000 reagent (Thermo Fisher Scientific) overnight. 
After overnight incubation, transfected cells were harvested and seeded in a 384-well optical-bottom microplate (PerkinElmer, MA, USA) at a density of 3000 cells/well. After the 24 -h incubation at $37{ }^{\circ} \mathrm{C}$, cells were treated with different concentrations of compounds for $1 \mathrm{~h}$. Cells were then fixed with $4 \%$ paraformaldehyde and stained with $1 \mu \mathrm{g} / \mathrm{ml}$ of Hoechst33342 (Thermo Fisher Scientific). Cell images of 9 visual fields per well were acquired with $\mathrm{a} \times 20$ objective lens using an Opera Phenix High-Content Screening System (PerkinElmer) and were analysed using Harmony4.9 software (PerkinElmer). Because protein-protein interactions are quantified by measuring the aggregation of fluorescent elements in foci, the fluorescent intensity in foci was normalized by the total fluorescence intensity in each cell. $\mathrm{EC}_{50}$ values were calculated using TIBCO Spotfire 10.3 software (PerkinElmer).

Cytotoxicity assay. The procedure follows our previous work ${ }^{2}$. The cytotoxic activities of isolated rapamycin derivatives against $\mathrm{T}$ lymphoma Jurkat cells, human ovarian adenocarcinoma SKOV-3 cells and malignant pleural mesothelioma MESO-1 cells were examined. Jurkat cells were cultured in RPMI1640 medium supplemented with $10 \%$ foetal bovine serum, penicillin $(50 \mathrm{U} / \mathrm{mL})$, streptomycin $(50 \mu \mathrm{g} / \mathrm{mL})$ and Glutamax. SKOV-3 cells were cultured in DMEM medium supplemented with $10 \%$ fetal bovine serum, penicillin $(50 \mathrm{U} / \mathrm{mL})$ and streptomycin $(50 \mu \mathrm{g} / \mathrm{mL})$. MESO-1 cells were cultured in RPMI1640 medium supplemented with $10 \%$ fetal bovine serum, penicillin $(50 \mathrm{U} / \mathrm{mL})$ and streptomycin $(50 \mu \mathrm{g} / \mathrm{mL})$. All cell lines were seeded in a 384 -well plate at a density of 1000 cells/well in $20 \mu \mathrm{L}$ of media and were incubated at $37^{\circ} \mathrm{C}$ in a humidified incubator with $5 \%$ $\mathrm{CO}_{2}$. After $4 \mathrm{~h}$ of incubation, samples diluted twofold in DMSO were added to the cell culture at a concentration of $0.5 \%(0.1 \mu \mathrm{L})$ and were incubated for $72 \mathrm{~h}$. Cell viabilities were measured using a CellTiter-Glo luminescent cell viability assay and an EnVision multilabel plate reader.

\section{Data availability}

All data generated or analyzed during this study are included in this published article and its Supplementary Information file.

Received: 17 December 2020; Accepted: 14 April 2021

Published online: 11 May 2021

\section{References}

1. Klaus, M. \& Grininger, M. Engineering strategies for rational polyketide synthase design. Nat. Prod. Rep. 35, 1070-1081 (2018).

2. Kudo, K. et al. In vitro Cas9-assisted editing of modular polyketide synthase genes to produce desired natural product derivatives. Nat. Commun. 11, 4022 (2020).

3. Peng, H., Ishida, K., Sugimoto, Y., Jenke-Kodama, H. \& Hertweck, C. Emulating evolutionary processes to morph aureothin-type modular polyketide synthases and associated oxygenases. Nat. Commun. 10, 3918 (2019).

4. Miyazawa, T., Hirsch, M., Zhang, Z. \& Keatinge-Clay, A. T. An in vitro platform for engineering and harnessing modular polyketide synthases. Nat. Commun. 11, 80 (2020).

5. Komatsu, M., Uchiyama, T., Omura, S., Cane, D. E. \& Ikeda, H. Genome-minimized Streptomyces host for the heterologous expression of secondary metabolism. Proc. Natl. Acad. Sci. U. S. A. 107, 2646-2651 (2010).

6. Komatsu, M. et al. Engineered Streptomyces avermitilis host for heterologous expression of biosynthetic gene cluster for secondary metabolites. ACS Synth. Biol. 2, 384-396 (2013).

7. Raju, R. et al. Nocardiopsins: New FKBP12-binding macrolide polyketides from an Australian marine-derived actinomycete Nocardiopsis sp. Chemistry (Easton) 16, 3194-3200 (2010).

8. Wlodek, A. et al. Diversity oriented biosynthesis via accelerated evolution of modular gene clusters. Nat. Commun. 8, 1206 (2017).

9. Zhang, L. et al. Characterization of giant modular PKSs provides insight into genetic mechanism for structural diversification of aminopolyol polyketides. Angew. Chem. Int. Ed Engl. 56, 1740-1745 (2017).

10. Keatinge-Clay, A. T. Polyketide synthase modules redefined. Angew. Chem. Int. Ed Engl. 56, 4658-4660 (2017).

11. Kuscer, E. et al. Roles of rapH and rapG in positive regulation of rapamycin biosynthesis in Streptomyces hygroscopicus. J. Bacteriol. 189, 4756-4763 (2007).

12. McAlpine, J. B., Swanson, S. J., Jackson, M. \& Whittern, D. N. Revised NMR assignments for rapamycin. J. Antibiot. (Tokyo) 44, 688-690 (1991).

13. Watanabe, T. et al. Genetic visualization of protein interactions harnessing liquid phase transitions. Sci. Rep. 7, 46380 (2017).

14. McDaniel, R. et al. Multiple genetic modifications of the erythromycin polyketide synthase to produce a library of novel "unnatural" natural products. Proc. Natl. Acad. Sci. USA 96, 1846-1851 (1999).

15. Waldron, C. et al. Cloning and analysis of the spinosad biosynthetic gene cluster of Saccharopolyspora spinosal1The DNA sequence reported here was deposited in GenBank under the accession number AY007564. Chem. Biol. 8, 487-499 (2001).

16. Kumar, P., Koppisch, A. T., Cane, D. E. \& Khosla, C. Enhancing the modularity of the modular polyketide synthases: transacylation in modular polyketide synthases catalyzed by malonyl-CoA:ACP transacylase. J. Am. Chem. Soc. 125, 14307-14312 (2003).

17. Annaval, T., Paris, C., Leadlay, P. F., Jacob, C. \& Weissman, K. J. Evaluating ketoreductase exchanges as a means of rationally altering polyketide stereochemistry. ChemBioChem 16, 1357-1364 (2015).

18. Massicard, J. M., Soligot, C., Weissman, K. J. \& Jacob, C. Manipulating polyketide stereochemistry by exchange of polyketide synthase modules. Chem. Commun. (Camb.) 56, 12749-12752 (2020).

19. Gregory, M. A. et al. Rapamycin biosynthesis: Elucidation of gene product function. Org. Biomol. Chem. 4, 3565-3568 (2006).

20. Holt, D. A. et al. Design, synthesis, and kinetic evaluation of high-affinity FKBP ligands and the X-ray crystal structures of their complexes with FKBP12. J. Am. Chem. Soc. 115, 9925-9938 (2002).

21. Liang, J., Choi, J. \& Clardy, J. Refined structure of the FKBP12-rapamycin-FRB ternary complex at 2.2 A resolution. Acta Crystallogr. D Biol. Crystallogr. 55, 736-744 (1999).

22. Wu, X. et al. Creating diverse target-binding surfaces on FKBP12: synthesis and evaluation of a rapamycin analogue library. ACS Comb. Sci 13, 486-495 (2011).

23. Kim, J. H., Komatsu, M., Shin-Ya, K., Omura, S. \& Ikeda, H. Distribution and functional analysis of the phosphopantetheinyl transferase superfamily in Actinomycetales microorganisms. Proc. Natl. Acad. Sci. U. S. A. 115, 6828-6833 (2018).

24. Chu, G., Vollrath, D. \& Davis, R. W. Separation of large DNA molecules by contour-clamped homogeneous electric fields. Science 234, 1582-1585 (1986). 


\section{Acknowledgements}

This work was supported in part by the Japan Agency for Medical Research and Development (AMED) under Grant Number JP20ae0101045 for K.S. and in part by JSPS KAKENHI Grant Number 19K15744 for K.K.

\section{Author contributions}

Conceptualization, K.K. and K.S.; data curation, K.K. and T.N.; funding acquisition, K.S.; investigation, K.K., T.N., I.K., J.H. and N.K.; methodology, K.K., T.N. and K.S.; project administration, K.S.; resources, H.I. and K.S.; supervision, K.S.; validation, K.K., T.N., H.S. and K.S.; visualization, K.K. and T.N.; writing-original draft, K.K. and T.N.; writing-review and editing, all authors.

\section{Competing interests}

The authors declare no competing interests.

\section{Additional information}

Supplementary Information The online version contains supplementary material available at https://doi.org/ 10.1038/s41598-021-88583-Z.

Correspondence and requests for materials should be addressed to K.S.

Reprints and permissions information is available at www.nature.com/reprints.

Publisher's note Springer Nature remains neutral with regard to jurisdictional claims in published maps and institutional affiliations.

(c) (i) Open Access This article is licensed under a Creative Commons Attribution 4.0 International License, which permits use, sharing, adaptation, distribution and reproduction in any medium or format, as long as you give appropriate credit to the original author(s) and the source, provide a link to the Creative Commons licence, and indicate if changes were made. The images or other third party material in this article are included in the article's Creative Commons licence, unless indicated otherwise in a credit line to the material. If material is not included in the article's Creative Commons licence and your intended use is not permitted by statutory regulation or exceeds the permitted use, you will need to obtain permission directly from the copyright holder. To view a copy of this licence, visit http://creativecommons.org/licenses/by/4.0/.

(C) The Author(s) 2021 